\title{
Qualities of Cookie Made With Beeswax-Coconut Oil Organogels as Replacement for Shortening
}

\author{
Wen-Chieh Sung*, Yu-Chin Lin \\ Department of Food Science, National Taiwan Ocean University, Keelung, R.O.C \\ *Corresponding author: sungwill@mail.ntou.edu.tw
}

\begin{abstract}
The effects of beeswax-coconut oil organogels (7.5\%, 10.0\%, 12.5\%, 15.0\% and 17.5\% beeswax, wt) quality-related characteristics of shortening replaced cookies were evaluated. The following quality attributes were measured: organogels melting points, fatty acids contents, proximate composition, color, texture, spread factor, sensory evaluation, antioxidant activity and storage stability. Peroxide values of cookie extracts made with organogels were dramatically lower than that of cookie made with shortening $(\mathrm{p}<0.05)$ which had a value of more than $10 \mathrm{meq} / \mathrm{kg}$ lipids, after 12 days storage at $60^{\circ} \mathrm{C}$ and strong oil rancid odor. All cookies made with organogels stored at $60^{\circ} \mathrm{C}$ for 20 days had peroxide values lower than $1.5 \mathrm{meq} / \mathrm{kg}$ lipids and no rancid odor, indicating the cookie was still in low oxidation condition. No significant differences were found in cookie dough texture, proximate composition, spread factor, reducing power. The melting point, texture profile of hardness and adhesiveness increased significantly with beeswax ratio increase in organogel. The total phenolic content of cookie extracts increases slightly $(\mathrm{p}>0.05)$, nevertheless, the antioxidant activity of cookie extracts with light or without light exposure for 2 hours decreases slightly. No significant differences in sensory attributes of cookies made with shortening and $12.5 \%$ beeswax-coconut oil organogel except crisp were revealed by 72 panelists. For cookie made with coconut oil, the oil separate out problem after baking was solved by adding more than $12.5 \%$ beeswax in organogel. Accordingly, cookies made with $12.5 \%$ beeswax-coconut oil organogel is considered the most acceptable and appropriate practice in processing cookies for commercial purposes of shortening replacement.
\end{abstract}

Keywords: Coconut oil, beeswax, organogel, cookie, antioxidation

Cite This Article: Wen-Chieh Sung, and Yu-Chin Lin, "Qualities of Cookie Made With Beeswax-Coconut Oil Organogels as Replacement for Shortening” Journal of Food and Nutrition Research, vol. 5, no. 9 (2017): 697-707. doi: 10.12691/jfnr-5-9-10.

\section{Introduction}

Epidemiologic study demonstrated that the consumption of high amounts of saturated fat and cholesterol induces high blood cholesterol [1]. Coconuts have served mankind as important foods for thousands of years. Coconut oil contains mostly (>90\%) of saturated fatty acids and it has received bad reputation to be hypercholesterolemic in action [2,3]. Clinical studies have revealed the consumption of coconut was not associated with cardiovascular disease and heart attacks [4]. Virgin coconut oil (VCO), which refers to coconut oil produced from coconut milk by natural or mechanical method (wet method). VCO is increasing in popularity as functional oil [3]. The VCO is rich in medium chain fatty acids which are associated with increase in the serum triacylglycerol but incorporation of structured lipid and other functional substances improving the lipid profile [5]. Nevin and Rajamohan [6] found low density lipoprotein (LDL) cholesterol in VCO fed aminals was decrease and high density lipoprotein (HDL) cholesterol was increase. Although, only trace amount $\alpha$-tocopherol in VCO, which contained high amount of total phenolics [7] and VCO was shown superior in antioxidant action [2].
Shortening prevents the formation of gluten during pastry, cake and cookie dough mixing. It also gives the tender texture and mouthfeel of baked products [8]. Shortening also imparts other functional characteristics such as aeration, stability, positively contributing to the geometry and structure of the baked products [9]. A great deal of effort has been made to reduce the use of shortening due to the possible presence of trans fatty acids and a high level of saturated fatty acids with the recent healthy trend [9]. It is possible to apply virgin coconut oil (VCO) to baked products instead of shortening, however, the use of VCO might produce baked products with more greasy and less crispy characteristic because its low melting point.

Orgnogels are defined as 3-dimensional networks of an organic phase produced by adding some organogelators into the liquid phase. Organogels have some advantages such as not changing the fatty acid composition; therefore, no trans and saturated fatty acids are produced [10,11,12]. The organogels were stable against oxidation during storage and their melting point was higher [13]. Coconut oil organogels might be used as margaring-like or shortening foot stock. Beeswax is regarded as a food additive approved by the US FDA. Through organolation with beeswax, coconut oil can be entrapped in organogelator and produced a solid-like gel network, organogel. 
In this study, the oleogels of virgin coconut oil with beeswax were prepared and they were incorporated into the formulation of cookies as a shortening replacer. The effects of organogels on the physicochemical properties of the cookies were investigated. The effect of the amount of beeswax supplement on the dough texture, baked cookie, cookie storage stability, antioxidant ability and consumer acceptance was evaluated.

\section{Materials and Methods}

\subsection{Raw Materials and Organogel Preparation of Coconut Oil with Beeswax}

Virgin coconut oil was obtained from Bakerking International Corp (Taipei, Taiwan). Beeswax was purchased from Bee-World Company (Taoyuan city, Taiwan). Sucrose, brown sucrose, nonfat dry milk, high-fructose corn syrup, and salt were purchased from a local market. Cake flour used in this study was purchased from the Cha Hwa corporation (Taichung, Taiwan). Sodium bicarbonate, all-purpose shortening, food grade sodium bicarbonate and ammonium bicarbonate were obtained from a local store (Fu Shen baking ingredient store, Keelung, Taiwan). Kjeldahl catalyst tablets, sodium hydroxyl, boric acid, sulfuric acid, methyl red 1,1-diphenyl-2picrylhydrazyl, ferrous chloride 4-hydrate, and ferrozine (3-(2-pyridyl)-5,6-bis(4-phenylfulfonic acid)-1,2,4-triazine were purchased from Panreac Appli Chem (Gatersleben, Saxony-Anhalt, Germany). All reagents used were of analytical grade. Acetone, methanol, ethanol, trichloracetic acid, and acetic acid were purchased from Sigma Aldrich (St. Louis Missouri, USA). Monobasic sodium phosphate dibasic sodium phosphate, methyl red, and sulfuric acid were purchased from Merck (Whitehouse station, NJ, USA). Ethyl ether was purchased from Nihon Shiyaku industries (Taiwan, R.O.C.).

Virgin coconut oil was replaced with beeswax at $7.5 \%$, $10.0 \%, 12.5 \%, 15.0 \%, 17.5 \%$ levels. The mixtures were heated at $80^{\circ} \mathrm{C}$ in a water bath to dissolve the beeswax and cooled down to room temperature $\left(22.5^{\circ} \mathrm{C}\right)$ for 24 hours and then stored at refrigerator $\left(7^{\circ} \mathrm{C}\right)$.

\subsection{Thermal Analysis, Fatty Acid Content and Texture Profile Analysis of Organogels}

The method of AOCS [14] was adapted for thermal analysis of organogels. All samples were analyzed with a Mettler Toledo DSC822e Differential Scanning Calorimeter (DSC) (Mettler Toledo, Swiss) according to the method of Dodd and Tonge [15]. Around 10-15 mg of each organogel mixture was weighed into an aluminum pan. The following temperature program was used: heating from $10^{\circ} \mathrm{C}$ to $80^{\circ} \mathrm{C}$ by $10^{\circ} \mathrm{C} / \mathrm{min}$. The pan was purged with dry nitrogen to prevent oxidation of organogel sample at flow rate of $80 \mathrm{ml} / \mathrm{min}$. Lipid extraction was determined by homogenizing $15 \mathrm{~g}$ cookie samples with $150 \mathrm{ml}$ chloroform-methanol mixture (2:1; $\mathrm{v} / \mathrm{v}$ ) containing $0.2 \%$ butylated hydroxytoluene (BHA) as antioxidant. Fatty acids were esterified into methyl esters according to AOAC [16].
VCO with beeswax at different levels were heated at $80^{\circ} \mathrm{C}$ in a water bath to dissolve the beeswax and poured separately into $250 \mathrm{ml}$ beaker and cooled down to room temperature $\left(22.5^{\circ} \mathrm{C}\right)$ for 24 hours. Hardness and adhesiveness test were performed following the method of Lima and Guraya [17]. A TA-XT2 Texture Analyzer (Stable Micro Systems Co., Ltd., Haslemere, England) with a cylinder probe (P/25, $25 \mathrm{~mm}$ in diameter) was used to compress organogel samples at $10.00 \mathrm{~mm} / \mathrm{s}$ to $50 \%$ target value (trigger load: $0.5 \mathrm{~g}$ ) from the sample surface and withdrawn at the same speed. The maximum force during compression was recorded. The test was performed in triplicate and the average maximum force is reported as hardness in Newton $(\mathrm{N})$. Adhesiveness is the force required to remove the probe from the organogel.

\subsection{Cookie Formulation and Preparation}

A single-bowl mixing procedure was used for making cookies according to AACC [18] method 10-54, with some modification. Appropriate amounts of dry ingredients (sucrose (20.0 g), brown sugar (16.0 g), salt (2.0 g), sodium bicarbonate (1.6 g) and nonfat dry milk $(1.6 \mathrm{~g})$ were weighed and mixed to give a uniform mixture. All-purpose shortening (64.0 g)) was weighed and the dry ingredients were added on top in the mixing bowl. The shortening and dry ingredients were mixed at low speed using a Kitchen Aid mixer (St. Joseph, MI, USA) for 3 min and scraped down after each minute. The flour (160.0 g) was added and mixed at low speed for 1 min and scraped down every $20 \mathrm{~s}$. High-fructose corn syrup (2.4 g) and ammonium bicarbonate $(0.8 \mathrm{~g})$ was dissolved in the water (35.2 g) and added into the mixing bowl. The shortening in the cookie formula was replaced by $100 \%$ coconut oil, and $7.5 \%, 10.0 \%, 12.5 \%, 15.0 \%$ and $17.5 \%$ levels of beeswax organogels. After the mixing was completed, the dough was removed from the mixing bowl and placed on an ungreased baking sheet between two identical cutting boards, and then rolled by rolling pin to desired thickness of $2 \mathrm{~mm}$. The dough was cut using an aluminium cookie cutter (60 mm diameter). The cut dough sheet was baked at $205^{\circ} \mathrm{C}$ for $7 \mathrm{~min}$. After baking the cookies were cooled to room temperature and stored in Ziploc bags at refrigerator $\left(7^{\circ} \mathrm{C}\right)$ until evaluated.

\subsection{Proximate Chemical Composition and Color of Cookie, Texture Profile Analysis of Cookie Dough and Cookie}

The proximate chemical composition of cookie was determined according to the Association of Official Analytical Chemists method [16]. Spread factor of cookies was measured from the ratio of average value of diameter and average value of thickness of cookies with some modification (The diameter of ten cookies was measured again after rotating each cookie to $90^{\circ} \mathrm{C}$ and then the average value of cookie diameter was calculated). Ten cookies were stacked on each other and their thickness was measured [19].

Texture profile analysis of cookie doughs were performed following the method of Tarancón et al. [20]. A TA-XT2 Texture Analyzer with an aluminum cylinder $\mathrm{P} / 25$ probe was used to double compress cookie doughs, 
which were rolled into $10 \mathrm{~mm}$ thickness and cut with cookie cutter (60 mm in diameter). Dough samples were compressed at $10.00 \mathrm{~mm} / \mathrm{s}$ to $30 \%$ depth (trigger load: 0.5 $\mathrm{g}$ and waiting time between the two cycles: $5 \mathrm{~s}$ ) from the dough surface and withdrawn at the same speed. The maximum force during compression was recorded. The test was performed in triplicate and the average maximum force is reported as hardness in Newton $(\mathrm{N})$. Adhesiveness is the force required to remove the probe from the dough. Springiness was expressed as a ratio of the height during the second compression divide by the original height during the first compression.

Hardness test of cookie was performed following the method of Tarancón et al. [20]. A TA-XT2 Texture Analyzer with a round probe (P/25A, $4 \mathrm{~mm}$ in diameter) was used to compress cookie samples at $1.00 \mathrm{~mm} / \mathrm{s}$ to 50\% target value (trigger load: $20.0 \mathrm{~g}$ and supports apart: $50 \mathrm{~mm}$ ). The maximum force during compression was recorded. The test was performed in triplicate and the average maximum force is reported as hardness in Newton (N).

The color of the cookie samples were examined with a spectrocolorimeter (TC-1800 MK II, Tokyo, Japan) using L (lightness), a (redness/greenness) and b (yellowness/blueness) color scale according to the method of Cruz-Romero et al. [21]. Both a white tile and a black cup were examined before the test to standardize the spectrocolorimeter. The color of the cooki samples was recorded after taking three measurements for each sample, and triplicate determinations were recorded for each treatment. The color difference

$$
\begin{aligned}
& \Delta \mathrm{E}=\left[(\Delta \mathrm{L})^{2}+(\Delta \mathrm{a})^{2}+(\Delta \mathrm{b})^{2}\right]^{1 / 2} \\
& \text { where } \Delta \mathrm{L}=\mathrm{L}_{\text {sample }}-\mathrm{L}_{\text {control }} ; \\
& \Delta \mathrm{a}=\mathrm{a}_{\text {sample }}-\mathrm{a}_{\text {control }} ; \Delta \mathrm{b}=\mathrm{b}_{\text {sample }}-\mathrm{b}_{\text {control }} \text {. }
\end{aligned}
$$

\subsection{Total Phenolics Content, Reducing Power and Antioxidant Activity Measured by $\beta$-Carotene Bleaching Method}

Cookie samples were milled and screened through a sieve $(0.5 \mathrm{~mm})$. The ground cookie samples were stored at $-20^{\circ} \mathrm{C}$. The ground cookie samples (3 g) were extracted with $22.5 \mathrm{ml}$ of a methanol:acetone:water (1:1:1; v/v/v) using a stirring hot plate (Model PC-420D, Corning, NY, USA) at $1000 \mathrm{rpm}$ for $30 \mathrm{~min}$ according to the method of Seczyk et al. [22] with slight modification. The extracts were centrifuged $(6800 \times g)$ at $4^{\circ} \mathrm{C}$ for $30 \mathrm{~min}$ and extraction procedure was repeated two times. All extracted solutions were combined and stored in darkness at $-20^{\circ} \mathrm{C}$ until analysis.

Total phenolics were evaluated using Folin-Ciocalteau reagent described by Singleton and Rossi [23]. The cookie extracted solution $(0.1 \mathrm{ml})$, water $(0.1 \mathrm{ml})$ and Folin-Ciocalteau reagent $(0.4 \mathrm{ml})$ were mixed, and then $2 \mathrm{ml}$ of sodium carbonate $(100 \mathrm{~g} / 1000 \mathrm{ml})$ was added after $3 \mathrm{~min}$ and mixed thoroughly. It was allowed to stand for $30 \mathrm{~min}$ and measured the absorbance at $700 \mathrm{~nm}$ in a microplate Reader (Model AMR-100, Allsheng Instruments Co., Ltd., Hangzhou City, China). Total phenolics content was calculated as gallic acid equivalents in $\mathrm{mg} / \mathrm{g}$ of dry weight.
A $1 \mathrm{ml}$ of cookie extracted solution was added to $1 \mathrm{ml}$ of sodium phosphate buffer $(0.2 \mathrm{mM}, \mathrm{pH}$ 6.6) followed by $1 \mathrm{ml}$ of $1 \%$ potassium ferricyanide. The reaction mixture was incubated for $20 \mathrm{~min}$ in a water bath at $50^{\circ} \mathrm{C}$. After incubation, $1 \mathrm{ml}$ of $10 \%$ trichloroacetic acid was added, followed by centrifugation at $1700 \times g$ for $10 \mathrm{~min}$ at $4{ }^{\circ} \mathrm{C}$. The upper layer $(1 \mathrm{ml})$ was mixed with $1 \mathrm{ml}$ distilled water and $0.2 \mathrm{ml}$ of $0.1 \%$ ferric chloride. Absorbance of the resulting solution was measured at $700 \mathrm{~nm}$. A reaction mixture containing $125 \mu \mathrm{l}$ of DI water served as the blank and $125 \mu \mathrm{l}$ ascorbic acid $(500 \mu \mathrm{M})$ served as the positive control. A high absorbance was indicative of strong reducing power [24].

Oxidative loss of $\beta$-carotene in a $\beta$-carotene linoleic acid emulsion was used to assess the antioxidant activity of the examined cookie extracts [25]. $\beta$-carotene $(1 \mathrm{mg})$ was dissolved in $10 \mathrm{ml}$ of chloroform and $3 \mathrm{ml}$ of $\beta$-carotene solution was mixed with $40 \mathrm{mg}$ of purified linoleic acid and $400 \mathrm{mg}$ of Tween 20 in around-bottom flask. Chloroform was removed by purging with nitrogen. Pure water $(100 \mathrm{ml})$ was added into the $\beta$-carotene/linoleic acid emulsion and subjected to Vertex shaking for $60 \mathrm{~s}$. Cookie extracts $(0.1 \mathrm{ml})$ and aliquots $(3 \mathrm{ml})$ of the $\beta$-carotene/linoleic acid emulsion were placed in capped culture tubes and mixed thoroughly. The tubes were placed with light exposure and without light exposure for 0,60 , and 120 minutes. Oxidation of $\beta$-carotene/linoleic acid emulsion was monitored spectrophotometrically by measuring the absorbance at $465 \mathrm{~mm}$ after 0,60 , and 120 minutes (AMR-100, All sheng Instruments Co., Ltd., Hangzhou city, China). A control was prepared using 0.1 $\mathrm{ml}$ of $95 \%$ ethanol instead of the extract.

$$
\begin{aligned}
& \text { Degradation rate }(\mathrm{DR})=\ln \left(\mathrm{A}_{0} / \mathrm{A}_{\text {sample }}\right) / \mathrm{t} \\
& \text { The antioxidant activity }(\% \mathrm{AOA}) \\
& =\left[\left(\mathrm{DR}_{\text {blank }}-\mathrm{DR}_{\text {sample }}\right) / \mathrm{DR}_{\text {blank }}\right] \times 100 \%
\end{aligned}
$$

Where $A_{0}$ is the initial absorbance (465 nm) at time zero, $\mathrm{A}_{\text {sample }}$ is the absorbance (465 nm) at time $120 \mathrm{~min}$ and $\mathrm{t}$ is time (min).

\subsection{Cookie Lipid Fraction Oxidation Measurements}

The lipids of grinded cookies (100 g) were extracted for $60 \mathrm{~min}$ with the use of petroleum ether in a laboratory shaker at ambient conditions [26]. After filtration and separation of lipid fraction, solvent was removed by evaporation under reduce pressure on rotary evaporator at $50^{\circ} \mathrm{C}$ (IKA RV-10 basica, IKA, Germany). The lipids obtained were frozen $\left(-18^{\circ} \mathrm{C}\right)$ until further use.

The antioxidant activity of the cookie prepared with coconut oil and beeswax organogel was evaluated by measuring the peroxide value (PV) in the solvent extracts of cookies [14]. The PV was measured by putting the cookie sample (5 g) into an Erlenmeyer flask (250 ml) and adding a glacial acetic acid/isooctane solution (3:2, v/v, 30 $\mathrm{ml})$. After nitrogen gas was flushed into the Erlenmeyer flask, a saturated potassium iodide solution $(1 \mathrm{ml})$ was added. The flask was immediately sealed, shaken gently for $1 \mathrm{~min}$, and allowed to stand in the dark for $5 \mathrm{~min}$. 
After distilled $(30 \mathrm{ml})$ was added with vigorous stirring, the solution was titrated with $0.01 \mathrm{~N}$ sodium thiosulfate solution, using a $1 \%$ starch solution $(400 \mu \mathrm{l})$ as the indicator.

$$
\begin{aligned}
& \mathrm{PV}(\mathrm{mg} / \mathrm{kg} \text { lipid })=(\mathrm{V} 2-\mathrm{V} 1) \times 0.01 \times 1000 / \mathrm{W} . \\
& \mathrm{V} 2-\mathrm{V} 1= \mathrm{ml} \text { of sodium thiosulphate }\left(\mathrm{Na}_{2} \mathrm{~S}_{2} \mathrm{O}_{3}\right) \\
&(\text { blank corrected }) .
\end{aligned}
$$

Stability of cookies was followed periodically after 0,4 , $8,12,16$, and 20 days of storage at $60^{\circ} \mathrm{C}$, by determining peroxide value (PV) and recording odor change during 20 days according to the method of Mildner-Szkudlarz et al. [27].

\subsection{Sensory Evaluation}

Thirty-two male and forty female undergraduate and graduate students from the Department of Food Science, between the ages of 18 and 24, were panel participants. Cooki samples were coded with three digits and panelists were instructed to evaluate the appearance, odor, crisp, flavor, coconut flavor and overall acceptability using a seven-point hedonic scale ranging from "1=extremely dislike" to "7=extremely like" according to the method of Sudha et al. [28].

\subsection{Statistical Analysis}

Data was examined with an analysis of variance using the SPSS statistic program for Windows Version 12 (SPSS Inc., Chiago, IL, USA). Ducan's multiple range test was used to identify the difference between treatments at a $5 \%$ significance level $(\mathrm{p}<0.05)$. Differences between the means were evaluated using Duncan's Multiple Range Test. [29]

\section{Results and Discussion}

\subsection{Thermal Analysis of Organogels and Fatty Acid Contents of Organogels}

The melting points of $7.5 \%$ and $10.0 \%$ beeswax organogels $\left(35.3^{\circ} \mathrm{C}\right.$ and $35.8^{\circ} \mathrm{C}$, respectively) were close to that of shortening $\left(34.3^{\circ} \mathrm{C}\right)$ (Table 1$)$. The main fatty acids of cookie made with shortening were palmatic acid (43\%) and oleic acid (40\%) with $0.4 \%$ trans fatty acid (Table 2). However, there were no trans fatty acid was found and the main fatty acids of beeswax-coconut oil organogels were lauric acid (46-48\%), myristic acid (18\%), palmatic acid (10-12\%) with less than $1 \%$ of lignoceric

\begin{tabular}{|c|c|c|c|c|c|c|c|}
\hline & Control & CNO & $\begin{array}{c}\mathrm{CNO}+\mathrm{BW} \\
(7.5 \%)\end{array}$ & $\begin{array}{c}\text { CNO + BW } \\
(10 \%)\end{array}$ & $\begin{array}{c}\mathrm{CNO}+\mathrm{BW} \\
(12.5 \%)\end{array}$ & $\begin{array}{c}\mathrm{CNO}+\mathrm{BW} \\
(15 \%)\end{array}$ & $\begin{array}{c}\text { CNO + BW } \\
(17.5 \%)\end{array}$ \\
\hline \multirow[t]{2}{*}{$\mathrm{T}_{\text {peak }}\left({ }^{\circ} \mathrm{C}\right)$} & $34.29 \pm 2.60^{\mathrm{a}}$ & $23.50 \pm 0.11^{\mathrm{b}}$ & $20.02 \pm 0.26^{\mathrm{c}}$ & $19.67 \pm 2.37^{c}$ & $19.57 \pm 1.44^{\mathrm{c}}$ & $19.97 \pm 1.15^{\mathrm{c}}$ & $23.18 \pm 1.57^{\mathrm{d}}$ \\
\hline & - & $27.67 \pm 0.17^{\mathrm{e}}$ & $50.61 \pm 0.45^{\mathrm{d}}$ & $52.04 \pm 0.19^{c}$ & $53.75 \pm 0.65^{\mathrm{b}}$ & $54.10 \pm 0.38^{\mathrm{b}}$ & $55.82 \pm 0.31^{\mathrm{a}}$ \\
\hline Melting point $\left({ }^{\circ} \mathrm{C}\right)$ & $34.29 \pm 2.60^{c}$ & $25.58 \pm 0.14^{\mathrm{d}}$ & $35.32 \pm 0.32^{\mathrm{bc}}$ & $35.85 \pm 1.16^{\mathrm{bc}}$ & $36.66 \pm 0.43^{b}$ & $37.04 \pm 0.42^{b}$ & $39.50 \pm 0.93^{\mathrm{a}}$ \\
\hline
\end{tabular}
acid (Table 2).

Table 1. Peak temperature and melting point of different concentrations of coconut oil and beeswax organogels

Control: commercial shortening; CNO: coconut oil; CNO + BW (7.5\%): 7.5\% beeswax-coconut oil organogels; CNO + BW (10\%): 10\% beeswaxcoconut oil organogels; CNO + BW (12.5\%): 12.5\% beeswax-coconut oil organogels; CNO + BW (15\%): 15\% beeswax-coconut oil organogels; CNO + BW (17.5\%): 17.5\% beeswax-coconut oil organogels. Expressed as mean \pm standard deviation ( $\mathrm{n}=3$ ). Values followed by the different letter within

\begin{tabular}{|c|c|c|c|c|c|c|c|c|}
\hline \multirow[t]{2}{*}{ Fatty acids (\%) } & \multicolumn{2}{|c|}{ Sample } & \multirow[b]{2}{*}{ CNO } & \multirow[b]{2}{*}{$\begin{array}{c}\mathrm{CNO}+\mathrm{BW} \\
(7.5 \%)\end{array}$} & \multirow[b]{2}{*}{$\begin{array}{c}\text { CNO + BW } \\
(10 \%)\end{array}$} & \multirow[b]{2}{*}{$\begin{array}{c}\text { CNO + BW } \\
(12.5 \%)\end{array}$} & \multirow[b]{2}{*}{$\begin{array}{c}\text { CNO + BW } \\
(15 \%)\end{array}$} & \multirow[b]{2}{*}{$\begin{array}{c}\text { CNO + BW } \\
(17.5 \%)\end{array}$} \\
\hline & Control & BW & & & & & & \\
\hline $6: 0$ & ND* & ND* & 0.63 & 0.66 & 0.65 & 0.65 & 0.65 & 0.63 \\
\hline 8:0 & ND* & ND* & 8.19 & 8.29 & 8.11 & 8.09 & 8.05 & 7.94 \\
\hline $10: 0$ & ND* & ND* & 6.33 & 6.24 & 6.14 & 6.11 & 6.06 & 6.00 \\
\hline 12:0 & 0.21 & 0.28 & 49.02 & 47.74 & 47.3 & 46.89 & 46.47 & 45.99 \\
\hline 14:0 & 1.12 & 0.44 & 19.05 & 18.27 & 18.20 & 18.00 & 17.85 & 17.67 \\
\hline $15: 0$ & 0.05 & 1.09 & ND* & ND* & ND* & 0.06 & 0.06 & 0.08 \\
\hline $16: 0$ & 42.98 & 66.28 & 8.40 & 9.63 & 10.23 & 10.69 & 11.16 & 11.76 \\
\hline $9 c-16: 1$ & 0.16 & 0.09 & ND* & ND* & ND* & ND* & ND* & ND* \\
\hline $17: 0$ & 0.10 & ND* & ND* & ND* & ND* & ND* & ND* & ND* \\
\hline 18:0 & 4.40 & 2.54 & 3.04 & 3.01 & 3.00 & 3.01 & 2.99 & 2.99 \\
\hline $9 c-18: 1$ & 39.58 & 11.19 & 4.5 & 4.85 & 4.87 & 4.93 & 4.97 & 5.03 \\
\hline 11c-18:1 & 0.71 & 0.13 & ND* & ND* & ND* & $\mathrm{ND}^{*}$ & $\mathrm{ND}^{*}$ & $\mathrm{ND}^{*}$ \\
\hline 9c,12c-18:2 & 9.31 & 0.78 & 0.64 & 0.68 & 0.68 & 0.68 & 0.67 & 0.67 \\
\hline $9 c, 12 t-18: 2$ & 0.18 & ND* & ND* & ND* & ND* & ND* & ND* & $\mathrm{ND}^{*}$ \\
\hline $9 t, 12 c-18: 2$ & 0.17 & ND* & ND* & ND* & ND* & ND* & ND* & ND* \\
\hline 9c,12c,15c-18:3 & 0.17 & 0.28 & ND* & ND* & ND* & $\mathrm{ND}^{*}$ & ND* & $\mathrm{ND}^{*}$ \\
\hline 20:0 & 0.39 & 0.35 & 0.09 & 0.10 & 0.10 & 0.10 & 0.10 & 0.11 \\
\hline 11C-20:1 & 0.15 & 0.68 & ND* & ND* & 0.05 & 0.06 & 0.08 & 0.10 \\
\hline 22:0 & 0.09 & 1.21 & $\mathrm{ND}^{*}$ & 0.05 & 0.06 & 0.08 & 0.08 & 0.10 \\
\hline 24:0 & 0.09 & 14.67 & $\mathrm{ND}^{*}$ & 0.36 & 0.51 & 0.62 & 0.76 & 0.91 \\
\hline Trans fatty acids & 0.35 & ND* & ND* & ND* & ND* & ND* & ND* & ND* \\
\hline
\end{tabular}
each column are significantly different $(p<0.05)$.

Table 2. Fatty acids contents of commercial shortening, beeswax and organogels

Control: commercial shortening; CNO: coconut oil; CNO + BW (7.5\%): 7.5\% beeswax-coconut oil organogels; CNO + BW (10\%): 10\% beeswaxcoconut oil organogels; CNO + BW (12.5\%): 12.5\% beeswax-coconut oil organogels; CNO + BW (15\%): 15\% beeswax-coconut oil organogels; CNO + BW (17.5\%): 17.5\% beeswax-coconut oil organogels.

$*$ ND $=$ not detectable. 


\subsection{Texture Properties of the Organogel, Cookie Dough and Cookies}

Hardness and adhesiveness of the organogels were measured at room temperature $\left(22.5^{\circ} \mathrm{C}\right)$ and presented in Figure 1 . Organogels made with $15 \%$ beeswax have shown a significant increase in the hardness and adhesiveness values. The hardness and adhesiveness values of all-purpose shortening (control) were $0.99 \mathrm{~N}$ and $0.35 \mathrm{~N}$, respectively. Among all organogel samples, the hardness and adhesiveness of $10 \%$ beeswax organogel were close those of shortening. It showed no differences $(p>0.05)$ compared to the hardness and adhesiveness of shortening and organogels containing less than $12.5 \%$ beeswax. Hardness is the force required to compress a material under certain defined conditions. The stabilization of organogel structure is via non-covalent interactions like van der Waals interactions hydrogen bonding and others [12]. Beeswax contains straight-chain acids with carbon skeletons of up to 36, including some C18 hydroxyl acids that can be esters, diesters and triesters and straight-chain monohydric alcohol compounds with carbon chains from C24 to C36 [30]. The increase of beeswax concentration leads to higher values of hardness and adhesiveness, which could be associated with strengthened network of gels formed during crystallization process (Figure 1). The highest hardness and adhesiveness values were $13.75 \mathrm{~N}$ and $2.83 \mathrm{~N}$ for organogel made with $17.5 \%$ beeswax. Gels were shown to become stronger and sticker after adding beeswax. Similar trend was reported in cod liver oil organogels formed with beeswax and carnauba wax [31]. It was proposed due to progression of aggregates among the sterol-sterol ester assemblages of the $\beta$-sitosterol and $\gamma$-oryzanol organgelator used by Calligaris et al. [32]. The gel strength increases in the candelilla wax-sunflower oil organogels as organogelator (the Candelilla wax) concentration increases [10]. Those results agree with our findings. Very similar trends of changes were observed at another important texture parameter, adhesiveness for all samples and the above researches. Adhesiveness is the force required to remove a material from its surface. Some moderate levels of both hardness and adhesiveness are necessary for the shortening and margarine products for baking industry.

However, the low viscosity of the coconut oil when dough mixing and it melts causing a difficulty in shaping and handling, when coconut oil melts out the dough and it will enhance the cohesion of gluten strand forming during cookie dough mixing and it form a greasy and firmer cookie texture. There was no significant effect was found on cookie dough hardness, adhesiveness and springiness compared to that of cookie dough made with shortening (data not shown).

(A)

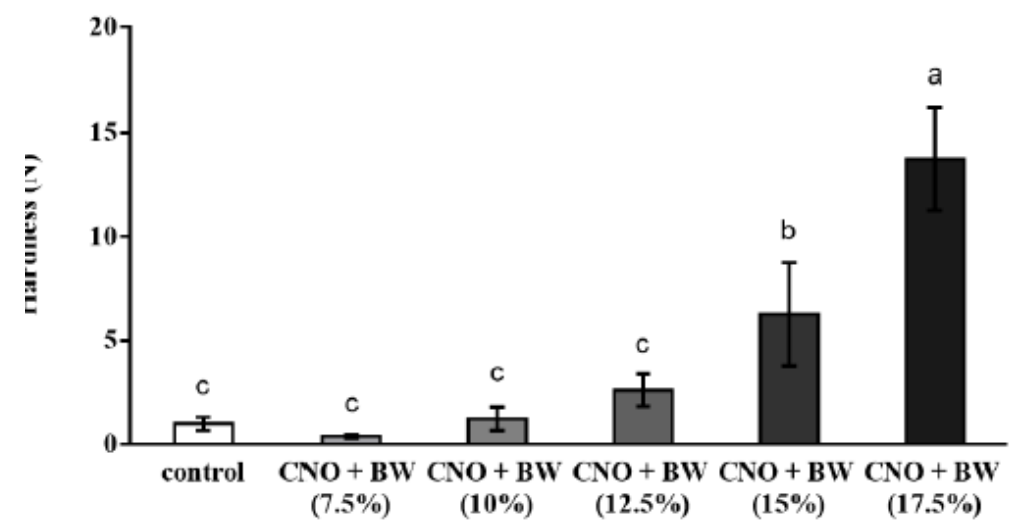

(B)

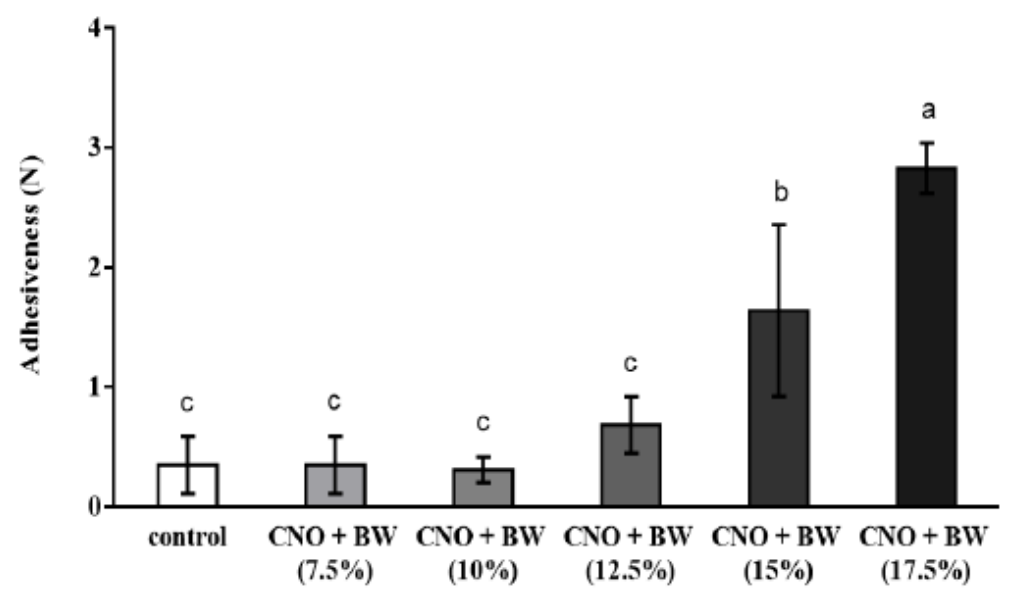

Control: commercial shortening; CNO + BW (7.5\%): 7.5\% beeswax-coconut oil organogels; CNO + BW (10\%): 10\% beeswax-coconut oil organogels; CNO + BW (12.5\%): 12.5\% beeswax-coconut oil organogels; CNO + BW (15\%): 15\% beeswax-coconut oil organogels; CNO + BW (17.5\%): 17.5\% beeswax-coconut oil organogels. Expressed as mean \pm standard deviation $(n=3)$.Values followed by the different letter within each column are significantly different $(p<0.05)$.

Figure 1. Properties of commercial shortening and organogels: hardness (A) and adhesiveness (B) 


\subsection{Cookie Chemical Composition and Spread Factor}

No significant differences were found between cookie control and tested groups for crude protein $(1.68 \%$ to $2.0 \%$ ), fat (22.79\% to $26.91 \%)$ and carbohydrate $(64.54 \%$ to $68.15 \%)(p>0.05)$ except moisture (3.72\% to $8.17 \%)$ and ash (1.57\% to $1.76 \%)$ content of cookies. The cookie of $7.5 \%$ beeswax-coconut oil organogels showed highest moisture content (8.17\%) and lowest ash content (1.57\%).

The spread factors of cookies made with beeswax coconut oil organogel were in the range of 7.9 to 11.9, which were not statistically significant $(p>0.05)$ to the spread factor (10.36) of cookie with the shortening (data not shown). The similar spread factor to the cookies made of shortening shows the amount of beeswax in this study would not affect the spread factor at application of cookie products. The spread factor was not much affected by $7.5 \%$ to $17.5 \%$ beeswax-coconut oil organogel. Our results agree with finding of that when added $2 \%$ to $10 \%$ of natural wax to olive oil and flaxseed oil organogel and their cookie spread factors were not affected [19].

Cookies made with organogel showed a decrease in cookie hardness compared to that with coconut oil (Figure 2), they were not statistically significant $(p>0.05)$ comparing to cookies made with shortening. Increasing the amount of beeswax from $7.5 \%$ to $17.5 \%$ in the organogel did not show a significant decrease in cookie hardness. The hardness of cookies with $12.5 \%, 15.0 \%$ and $17.5 \%$ beeswax coconut oil organogel $(4.90 \mathrm{~N}, 4.75 \mathrm{~N}$ and 4.95 $\mathrm{N}$, respectively) was similar to the hardness of the cookies with shortening (4.71 N, Figure 2) ( $>00.05)$. Jang et al. [9] proposed the cookies with the candelilla wax-canola oil organogel showed the replacement of shortening with organogel produced cookies with soft eating characteristics.

However, there was oil seperate out of cookies (Figure 3) when the cookie left on paper towel after baking specially for the cookies made with coconut oil and $7.5 \%$ to $10 \%$ beeswax organogel. The phenomenon was less observed at cookies made of shortening and $12.5 \%$ to $17.5 \%$ beeswax organogel (Figure 3 ). This result could be also attributed to the high hardness and adhesiveness of the organogel which play a positive role in prevent liquid coconut oil leak out during and after baking. The experiment results showed that the beeswax helps the formation of the three-dimensional network of the solid phase in the cookie matrix prevent liquid oil separating out [10].

The color of cookies play an important role in consumers' acceptability and perception of the cookie. Higher L value of $7.5 \%$ beeswax coconut oil organogel was observed. $\Delta \mathrm{E}$ of cookie made with $15.0 \%$ organogel was smallest (1.69) comparing to that of cookie made with shortening, which indicated the consumers might not be able to tell the color difference between these two products (data not shown).

\subsection{Determination of Total Phenolics Content, Reducing Power and Antioxidative Activity}

Addition of beeswax organogel increased the total phenolics content (Figure 4) of cookie. In comparison to the control, which is made with shortening, the content of phenolics in cookie extracts of $15.0 \%$ and $17.5 \%$ beeswax-coconut oil organogels were significantly higher (46.67 and 50.66 GAE/100 g sample, respectively) than that of control (23.47 GAE/100g sample) (Figure 4). It is due to the flavonoids present in beeswax [31]. These flavonoids are polyphenolics originate from honey and propolis. Tomas-Barberan et al. [33] examined the phenolic components of beeswax and found that it contained a family of flavonoids, the composition of which was identical with that of honey and propolis. The flavonoids were not characteristic of beeswax but, like propolis, were derived primarily from popular resin and from the honey. Beeswax is a complex mixture of chemical compounds predominantly based in straightchain monohydric alcohol compounds with carbon chains from C24 to C36 and straight-chain acids with carbon skeltons of up to C36, including some C18 hydroxyl acids that can be esters, diesters and triesters [30]. Beeswax consists of 70 to $71 \%$ total esters, 1 to $1.5 \%$ free alcohols, 9 to $11 \%$ free acids and 12 to $15 \%$ hydrocarbons [34,35].

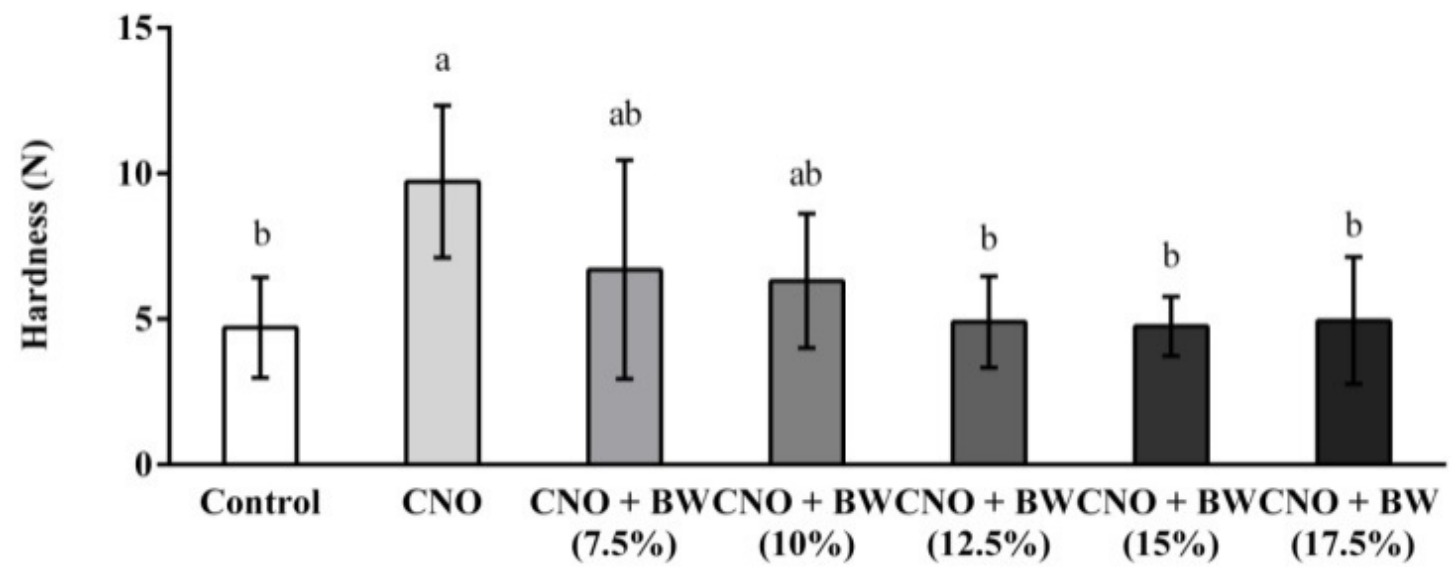

Control: commercial shortening; CNO: coconut oil; CNO + BW (7.5\%): 7.5\% beeswax-coconut oil organogels; CNO + BW (10\%): 10\% beeswaxcoconut oil organogels; CNO + BW (12.5\%): 12.5\% beeswax-coconut oil organogels; CNO + BW (15\%): 15\% beeswax-coconut oil organogels; CNO + BW (17.5\%): 17.5\% beeswax-coconut oil organogels. Expressed as mean \pm standard deviation $(\mathrm{n}=3)$.Values followed by the different letter within each column are significantly different $(p<0.05)$.

Figure 2. Comparison on hardness of cookie made with different concentrations of coconut oil and beeswax organogels. 

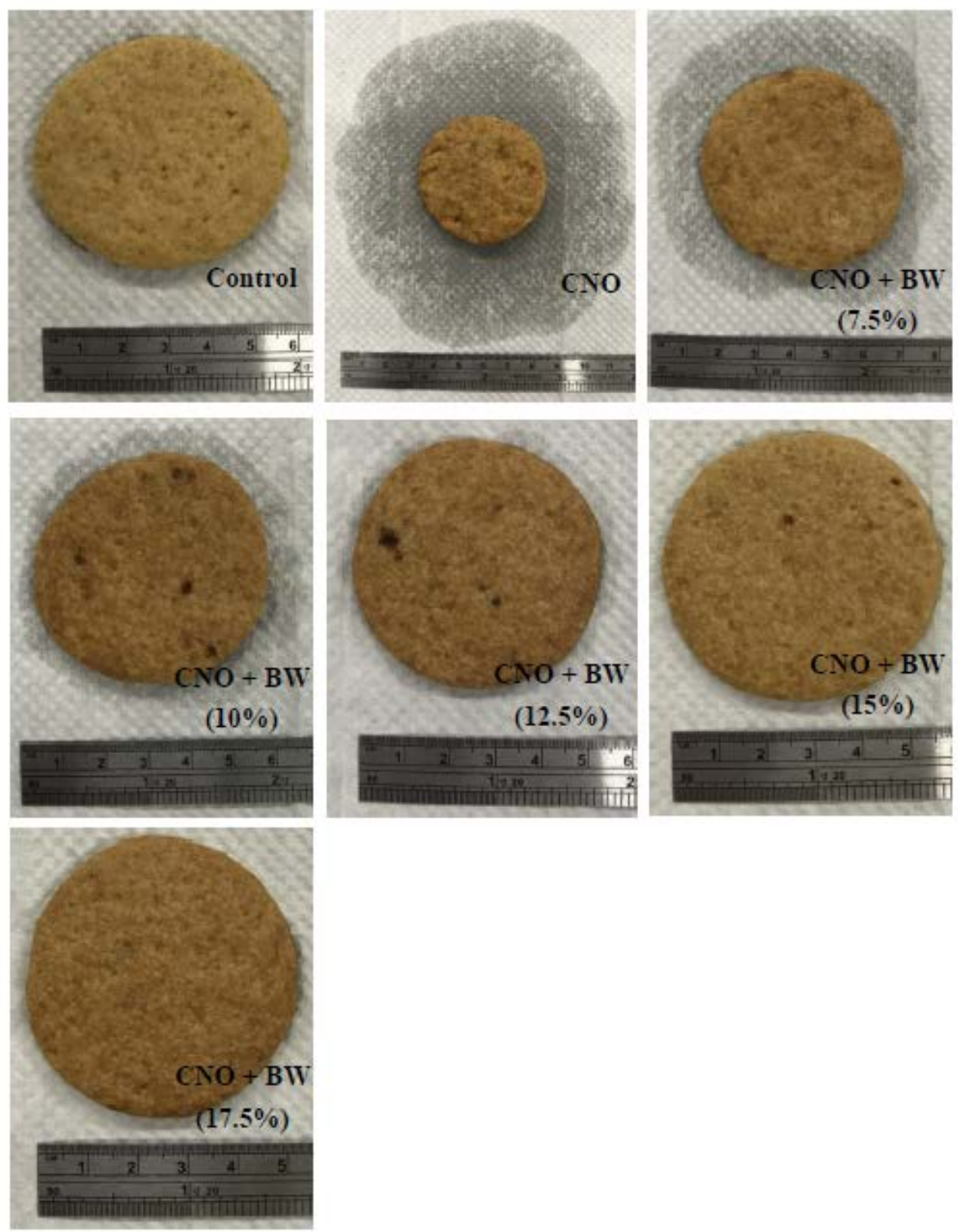

Control: commercial shortening; CNO: coconut oil; CNO + BW (7.5\%): 7.5\% beeswax-coconut oil organogels; CNO + BW (10\%): $10 \%$ beeswaxcoconut oil organogels; CNO + BW (12.5\%): 12.5\% beeswax-coconut oil organogels; CNO + BW (15\%): 15\% beeswax-coconut oil organogels; CNO + BW (17.5\%): 17.5\% beeswax-coconut oil organogels.

Figure 3. The oil spread pattern of cookie made with different concentrations of coconut oil and beeswax organogels

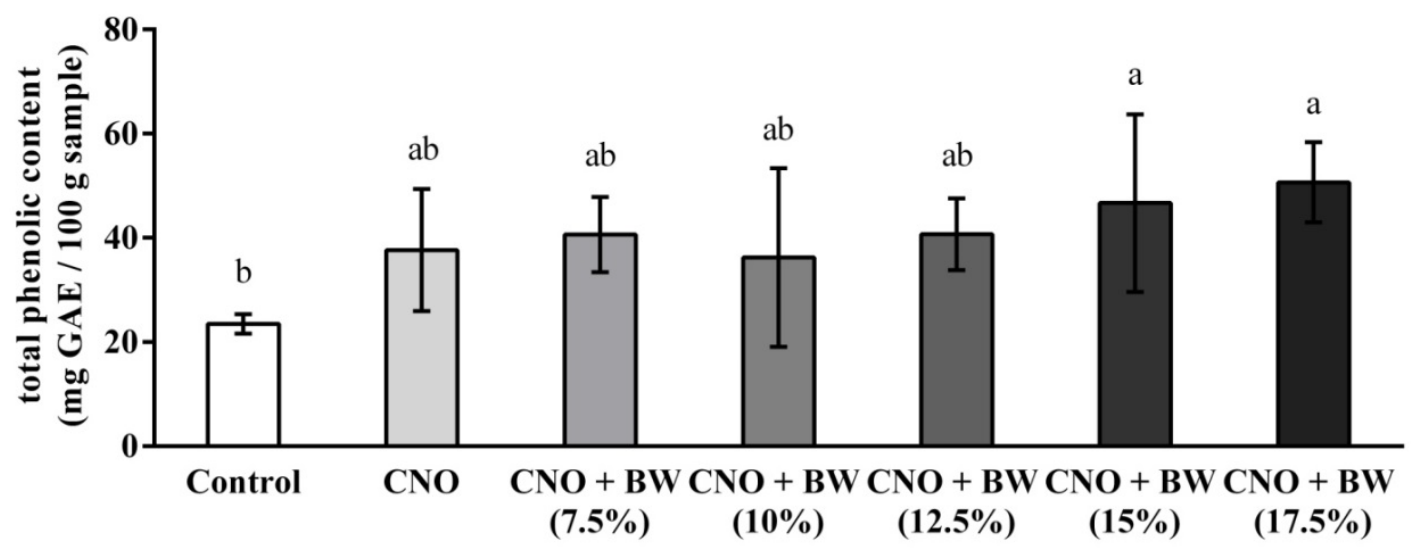

Control: commercial shortening; CNO: coconut oil; CNO + BW (7.5\%): 7.5\% beeswax-coconut oil organogels; CNO + BW (10\%): 10\% beeswaxcoconut oil organogels; CNO + BW (12.5\%): $12.5 \%$ beeswax-coconut oil organogels; CNO + BW (15\%): 15\% beeswax-coconut oil organogels; CNO + BW (17.5\%): $17.5 \%$ beeswax-coconut oil organogels. Expressed as mean \pm standard deviation $(n=3)$.Values followed by the different letter within each column are significantly different $(p<0.05)$.

Figure 4. Comparison on the total phenolic content of cookie extracts 
The reducing powers of cookie extracts are shown in Figure 5. The reducing power of cookies made with 15\% and $17.5 \%$ beeswax-coconut oil organogel exhibited lower value and they were lower than that of $10 \mu \mathrm{M}$ ascorbic acid $(p<0.05)$. It seems that beeswax addition decrease the reducing power of cookie extracts. However, the reducing power of cookies made with shortening and different organogels were not remarkable different ( $\mathrm{p}>0.05)$.

Antioxidative activities of cookie extracts with and without light exposure during 2 hours period at room temperature are demonstrated in the Figure $6 \mathrm{~A}$ and $6 \mathrm{~B}$, respectively. Clearly, antioxidative activities of cookies made with virgin coconut oil were always higher than those of control and $17.5 \%$ beeswax organogel. It may be due to beeswax replaced coconut oil in the organogel and it dilutes the antioxidative activity of cookie extract. There was a decrease trend in the antioxidative activity of cookie made with higher amount of beeswax under light exposure (Figure 6A). Antioxidative activity (38.16 and 43.39) of cookie made with $12.5 \%$ beeswax organogel was similar to that of control (40.38 and 39.01) with and without light exposure for 1 hour. However, the antioxidative activity of cookie made with $12.5 \%$ beeswax organogel was steady higher than that of control after 2 hours (Figure 6).

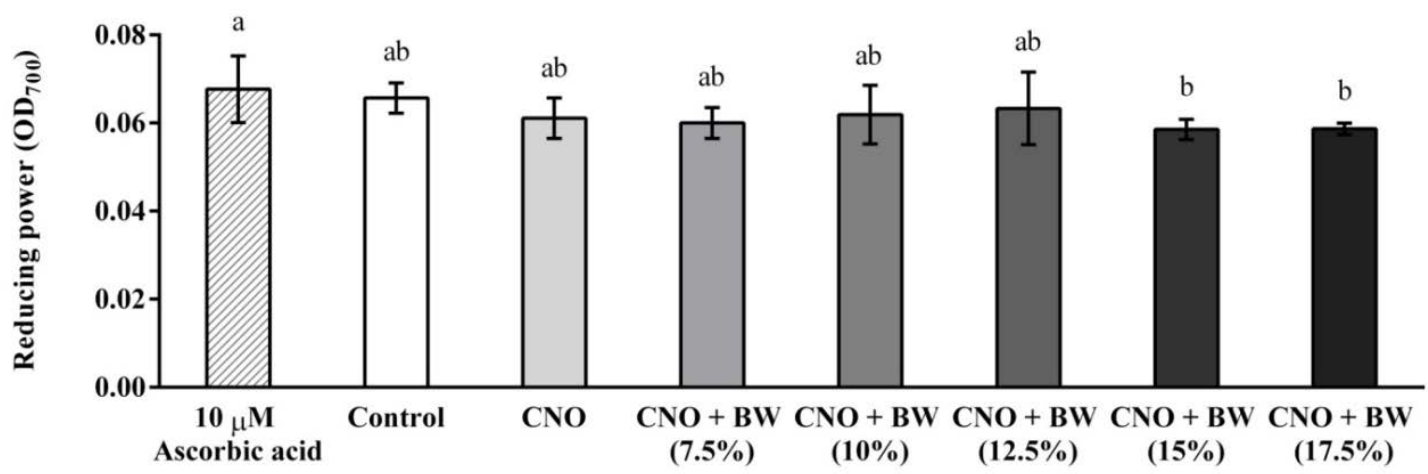

Control: commercial shortening; CNO: coconut oil; CNO + BW (7.5\%): 7.5\% beeswax-coconut oil organogels; CNO + BW (10\%): 10\% beeswaxcoconut oil organogels; CNO + BW (12.5\%): 12.5\% beeswax-coconut oil organogels; CNO + BW (15\%): 15\% beeswax-coconut oil organogels; CNO + BW (17.5\%): 17.5\% beeswax-coconut oil organogels. Expressed as mean \pm standard deviation ( $\mathrm{n}=3$ ). Values followed by the different letter within each column are significantly different $(p<0.05)$.

Figure 5. Comparison on the reducing power of cookie extracts

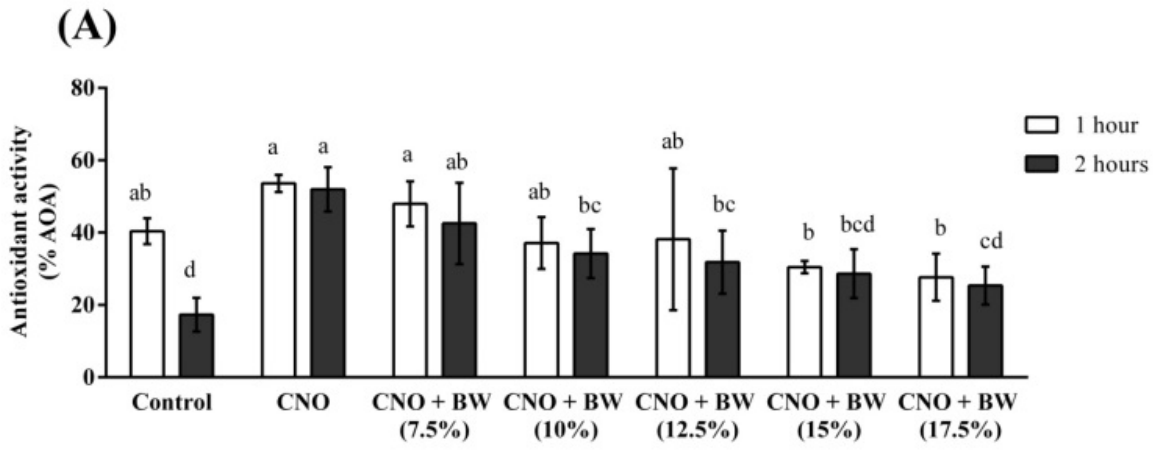

(B)

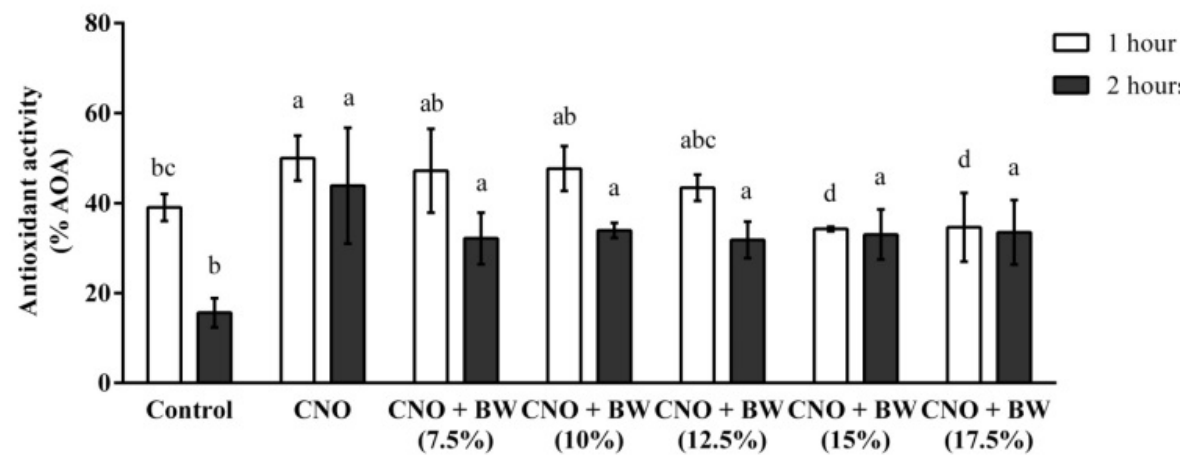

Control: commercial shortening; CNO: coconut oil; CNO + BW (7.5\%): 7.5\% beeswax-coconut oil organogels; CNO + BW (10\%): 10\% beeswaxcoconut oil organogels; CNO + BW (12.5\%): 12.5\% beeswax-coconut oil organogels; CNO + BW (15\%): 15\% beeswax-coconut oil organogels; CNO + BW (17.5\%): 17.5\% beeswax-coconut oil organogels. Expressed as mean \pm standard deviation ( $\mathrm{n}=3$ ). Values followed by the different letter within each column are significantly different $(p<0.05)$.

Figure 6. Comparison on the antioxidant activity of cookie extracts with light exposure (A) and without light explosure (B) 


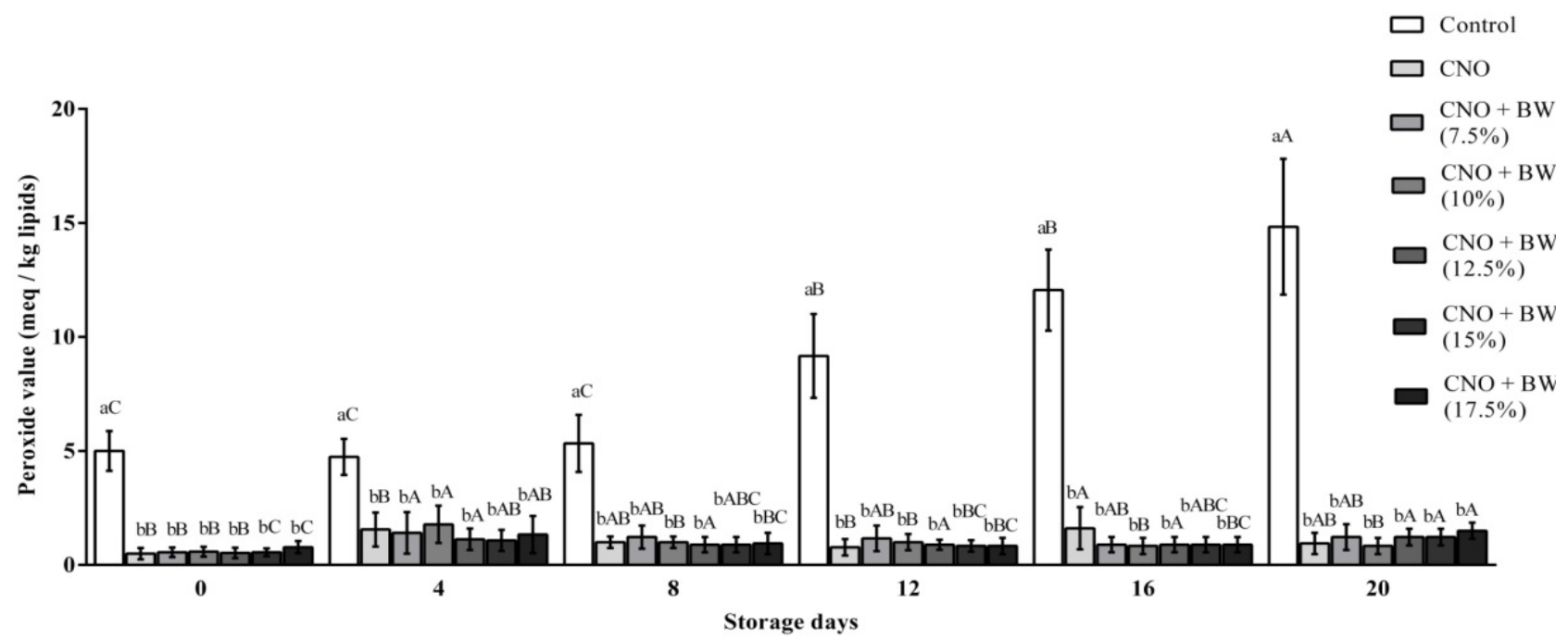

Control: commercial shortening; CNO: coconut oil; CNO + BW (7.5\%): 7.5\% beeswax-coconut oil organogels; CNO + BW (10\%): $10 \%$ beeswaxcoconut oil organogels; CNO + BW (12.5\%): $12.5 \%$ beeswax-coconut oil organogels; CNO + BW (15\%): $15 \%$ beeswax-coconut oil organogels; CNO + BW (17.5\%): $17.5 \%$ beeswax-coconut oil organogels. Expressed as mean \pm standard deviation $(n=3)$. Mean with superscripts of different small letters in the same columns are significantly different $(\mathrm{p}<0.05)$. Mean with superscripts of different capital letters in the same storage days of each sample are significantly different $(\mathrm{p}<0.05)$.

Figure 7. Effect of extracted lipids from cookie on the peroxide value during 20 days of stored at $60^{\circ} \mathrm{C}$

\subsection{Oxidative Stability of Cookies Made with Organogels during Storage}

At the beginning, peroxide value of extracted liquids from cookie made with shortening was $5 \mathrm{meq} / \mathrm{kg}$ lipids (Figure 7). Among all organogel samples, the peroxide values were in the range of 0.5 to $0.78 \mathrm{meq} / \mathrm{kg}$ lipids (Figure 7) after baking. There was a dramatically increase in peroxide value of control stored at $60^{\circ} \mathrm{C}$ for 20 days storage. Obviously, peroxide values of the cookies made with organogel were far below the $10 \mathrm{meq} / \mathrm{kg}$ liquids limit during 20 days storage at $60^{\circ} \mathrm{C}$. It was indicated that coconut oil and its beeswax organogels was effective against the development of first step oxidation.

Cookie made with commercial shortening still had strong butter aroma after 4 days storage at $60^{\circ} \mathrm{C}$. Nevertheless cookies made with organogels smelled more coconut aroma when it containing more beeswax. There was rancid aroma was detected in cookie made with shortening after 8 days storage at $60^{\circ} \mathrm{C}$. The odor of cookies made with organogels was similar to that of 4 days storage. When cookies made with shortening stored at $60^{\circ} \mathrm{C}$ for 12 days, the oil rancid aroma and butter flavor were strong. Among all organogel samples, coconut aroma and rancid flavor were barely detected after 12 days storage at $60^{\circ} \mathrm{C}$.
Studies also showed the ability of beeswax organogels to maintain aroma characteristics through time, as volatile compounds were successfully incorporated [36].

\subsection{Consumer Sensory Analysis}

The results for appearance, odor, flavor, crisp, coconut flavor and overall acceptability for the differ samples is shown in Table 3 . The appearance of the cookie made with shortening was rated higher (4.94) than that of cookies made with $7.5 \%$ and $15 \%$ beeswax organogels (4.54 and 4.51, respectively) (Table 3) $(\mathrm{p}<0.05)$. The odor, flavor, crisp and overall acceptability of cookies made with coconut oil and $15 \%$ beeswax organogels were significantly lower than that of control. There was no difference between control and $12.5 \%$ beeswax group in sensory attributes except crisp texture. Although sensory scores of the control were slightly higher than those of $12.5 \%$ beeswax organogel, it was still on acceptable range $(>4)$. The coconut flavor of all organogel samples was not significant higher than that of control. It indicates the difference was small ( $p>0.05$ ). The mean coconut flavor scores of all the cookies made with organogels were not over 4 , indicating they were acceptable to the consumers and the coconut flavor was not strong.

Table 3. The sensory evaluation analysis of cookie with different concentrations of coconut oil and beeswax organogels

\begin{tabular}{|c|c|c|c|c|c|c|}
\hline & Appearance & Odor & Flavor & Crisp & Coconut flavor* & Overall acceptability \\
\hline Control & $4.94 \pm 0.96^{\mathrm{a}}$ & $4.67 \pm 1.11^{\mathrm{a}}$ & $4.61 \pm 1.22^{\mathrm{a}}$ & $3.88 \pm 1.49^{\mathrm{a}}$ & $2.99 \pm 1.56^{\mathrm{a}}$ & $4.47 \pm 1.05^{\mathrm{a}}$ \\
\hline $\mathrm{CNO}$ & $4.57 \pm 1.17^{\mathrm{ab}}$ & $4.03 \pm 1.15^{\mathrm{b}}$ & $3.88 \pm 1.35^{\mathrm{c}}$ & $2.96 \pm 1.46^{\mathrm{cd}}$ & $2.82 \pm 1.60^{\mathrm{a}}$ & $3.96 \pm 1.43^{\mathrm{bc}}$ \\
\hline CNO + BW (7.5\%) & $4.54 \pm 1.05^{\mathrm{b}}$ & $4.44 \pm 1.06^{\mathrm{a}}$ & $4.4 \pm 1.17^{\mathrm{ab}}$ & $3.24 \pm 1.34^{\mathrm{bc}}$ & $3.04 \pm 1.44^{\mathrm{a}}$ & $4.15 \pm 1.04^{\mathrm{ab}}$ \\
\hline $\mathrm{CNO}+\mathrm{BW}(10 \%)$ & $4.63 \pm 0.96^{\mathrm{ab}}$ & $4.47 \pm 0.98^{\mathrm{a}}$ & $4.49 \pm 1.11^{\mathrm{ab}}$ & $3.63 \pm 1.40^{\mathrm{ab}}$ & $3.04 \pm 1.55^{\mathrm{a}}$ & $4.31 \pm 1.23^{\mathrm{ab}}$ \\
\hline CNO + BW (12.5\%) & $4.72 \pm 0.10^{\mathrm{ab}}$ & $4.42 \pm 1.15^{\mathrm{a}}$ & $4.47 \pm 1.02^{\mathrm{ab}}$ & $3.33 \pm 1.47^{\mathrm{bc}}$ & $3.24 \pm 1.52^{\mathrm{a}}$ & $4.35 \pm 1.14^{\mathrm{ab}}$ \\
\hline CNO + BW (15\%) & $4.51 \pm 1.07^{\mathrm{b}}$ & $3.96 \pm 1.12^{\mathrm{b}}$ & $3.72 \pm 1.10^{\mathrm{c}}$ & $2.63 \pm 1.18^{\mathrm{d}}$ & $2.81 \pm 1.30^{\mathrm{a}}$ & $3.58 \pm 1.06^{\mathrm{c}}$ \\
\hline CNO + BW (17.5\%) & $4.69 \pm 1.08^{\mathrm{ab}}$ & $4.29 \pm 1.20^{\mathrm{ab}}$ & $4.11 \pm 1.31^{\mathrm{bc}}$ & $3.19 \pm 1.39^{\mathrm{bc}}$ & $2.99 \pm 1.53^{\mathrm{a}}$ & $4.19 \pm 1.18^{\mathrm{ab}}$ \\
\hline
\end{tabular}

Control: commercial shortening; CNO: coconut oil; CNO + BW (7.5\%): 7.5\% beeswax-coconut oil organogels; CNO + BW (10\%): 10\% beeswaxcoconut oil organogels; CNO + BW (12.5\%): 12.5\% beeswax-coconut oil organogels; CNO + BW (15\%): 15\% beeswax-coconut oil organogels; CNO + BW (17.5\%): 17.5\% beeswax-coconut oil organogels. Expressed as mean \pm standard deviation ( $\mathrm{n}=72$ ). Values followed by the different letter within each column are significantly different $(p<0.05)$.

$1-7$ scale: 1 = dislike very much, 7 = like very much

$* 1-7$ scale: $1=$ none, $7=$ too strong. 
Table 4. Correlations of beeswax concentrations, total phenolic content, reducing power and antioxidant activity

\begin{tabular}{|c|c|c|c|c|c|c|c|}
\hline & $\begin{array}{l}\text { Beeswax } \\
\text { concentrations }\end{array}$ & Total phenolic content & Reducing power & $\begin{array}{l}\text { AOA } \\
\text { (light 1hr) }\end{array}$ & $\begin{array}{l}\text { AOA } \\
\text { (light 2hr) }\end{array}$ & $\begin{array}{l}\text { AOA } \\
\text { (dark 1hr) }\end{array}$ & $\begin{array}{l}\text { AOA } \\
\text { (dark 2hr) }\end{array}$ \\
\hline Beeswax concentrations & 1 & & & & & & \\
\hline Total phenolic content & 0.349 & 1 & & & & & \\
\hline Reducing power & -0.177 & $-0.534^{*}$ & 1 & & & & \\
\hline AOA (light 1hr) & $-0.739 * *$ & -0.370 & $0.525^{*}$ & 1 & & & \\
\hline AOA (light 2hr) & $-0.809 * *$ & -0.391 & 0.263 & $0.663^{* *}$ & 1 & & \\
\hline AOA (dark 2hr) & -0.455 & -0.275 & -0.460 & 0.271 & 0.265 & 0.099 & 1 \\
\hline
\end{tabular}

AOA (light 1hr): antioxidant activity with light exposure in 1 hour; AOA (light 2hr): antioxidant activity with light exposure in 2 hours; AOA (dark 1hr): antioxidant activity without light exposure in 1 hour; AOA (dark 2hr): antioxidant activity without light exposure in 2 hour.

${ }^{*}$ and ${ }^{* *}$ indicate significance at $\mathrm{p}<0.05$ and 0.01 respectively.

A correlation analysis was evaluated between the physicochemical properties in order to better understand the relationships among different quality attributes (Table 4). Beeswax ratio in organogel was negative correlated with the antioxidant activity of cookie extracts (Table 4).

\section{Conclusion}

Hardness and adhesiveness of organogels were significantly increased by adding up $15.0 \%$ beeswax. The significant increase on the organogel melting point was also observed in above $12.5 \%$ beeswax supplemented organogels. The melting points of $7.5 \%$ and $10.0 \%$ beeswax organogels were close to that of shortening $\left(34.3^{\circ} \mathrm{C}\right)$. There was no significant effect was found on cookie dough hardness, adhesiveness and springiness compared to that of cookie dough made with shortening. There was also no significant difference was observed on cookie hardness compared to that of cookie made with shortening. The use of coconut oil produces cookies with more greasy and less crispy characteristics. The hardness of cookie was significant decrease when beeswax organogel was used comparing to use coconut alone. Supplement of beeswax less than $10 \%$ in organogels led to a leaky oil phenomenon when the cookies put on the paper towel. Addition of beeswax can improve the problem and do not change the spread factor of cookie. Cookie made with beeswax organogel containing higher amounts of total phenolic content but lower reducing power. The antioxidant activity of cookie was mainly coming from coconut oil and it can prevent lipid oxidation of cookie stored at $60^{\circ} \mathrm{C}$ for 20 days. It was indicated that coconut oil and its beeswax organogels was effective against the development of first step oxidation. Coconut oil increases the storage stability, prevents oil oxidation and gives coconut flavor of the baked products. The main fatty acids of cookie made with shortening were palmatic acid and oleic acid with $0.4 \%$ trans fatty acid. However, there were no trans fatty acid was found and the main fatty acids of cookie made with beeswax-coconut oil organogels were lauric acid, myristic acid, palmatic acid with less than $1 \%$ of lignoceric acid. It is suggested $12.5 \%$ beeswax is feasible for utilization of beeswax-coconut oil organogel in cookie manufacture as replacement for commercial shortening.

\section{References}

[1] German GB, Dillard CJ. Saurated fats: what dietary intake? Am J Clin Nutr 80: 550-559, 2004.

[2] Nevin KG, Rajamohan T. Virgin coconut oil supplemented diet increases the antioxidant status in rats. Food Chem 99: 260-266, 2006.

[3] Marina AM, Che Man YB, Nazimah SAH, Amin I. Chemical properties of virgin coconut oil. J Am Oil Chem Soc 86: 301-307, 2009.

[4] Prior IA, Davidson F, Salmond CE, Czochanska Z. Cholesterol, coconuts and diet on Polynesian atolls: a natural experiment: the Pukapuka and Tokelan island studies. Am J Clin Nutr 34: 1552 1561, 1981.

[5] Che Man YB, Marina AM. Medium chain triacylglycerol. In: Nutraceutical and specialty lipids and their co-products, Shahidi, F., Ed.; CRC Press, Boca Raton, FL, 2006, 27-56.

[6] Nevin KG, Rajamohan T. Beneficial effects of virgin coconut oil on lipid parameters and in vitro LDL oxidation. Clinical Biochemistry 37: 830-835, 2004.

[7] Dia VP, Garcia VV, Mabesa RC, Tecsou-Mendoza EM. Coparative physiocochemical characteristics of virgin coconut oil produced by different methods. Philipp Agric Sci 88: 462-475, 2005.

[8] Gervajio G, Shahidi F. Bailey’s industrial oil and fat products. John Willey \& Sons Inc., New York, NY, 2005.

[9] Jang A, Bae W, Hwang HS, Lee HG, Lee S. Evaluation of canola oil oleogels with candelilla wax as an alternative to shortening in baked goods. Food Chem 187: 525-529, 2015.

[10] Toro-Vazquez JF, Morales-Rueda JA, Dibildox-Alvarado E, Charó-Alonso M, Alonzo-Macias M, González-Chávez MM. Thermal and textural properties of organogels developed by candelilla wax in safflower oil. J Am Oil Chem Soc 84: 989-1000, 2007.

[11] Marangoni AG, Garti N. Edible oleogels: structure and health implication. AOCS Press, Urbana, USA: 2011.

[12] Co ED, Marangoni AG. Organogels: An alternative edible oilstructuring method. J Am Oil Chem Soc 89: 749-780, 2012.

[13] Yilmaz E, Öğütcü M. Properties and stability of hazelnut oil organogels with beeswax and monoglyceride. J Am Oil Chem Soc 91: 1007-1017, 2014.

[14] AOCS. Official methods and recommended practices of the American Oil Chemists’ Society. 4th ed. Champaign, IL, USA, 1997.

[15] Dodd JW, Tonge KH. Thermal methods: Analytical Chemistry by Open Learning. Wiley, London, UK, 1987.

[16] AOAC. Official Methods of Analysis of the Association of Official Analytical Chemists. 16th ed. Sidney, W. Ed., Washington D.C.: AOAC, 1998.

[17] Lima IM, Guraya HS. Optimization analysis of sunflower butter. $J$ Food Sci 70: 365-370, 2005.

[18] AACC. Approved Methods of the American Association Cereal Chemists. $10^{\text {th }}$ ed. Methods 44-15A, 02-52, 76-21, 10-90, 10-05 St. Paul, MN, USA, 2000.

[19] Hwang HS, Singh M, Lee S. Properties of cookies made with natural wax-vegetable oil organogels. J Food Sci 81: 1045-1054, 2016. 
[20] Tarancón P, Salvador A, Sanz, T. Sunflower oil-water-cellulose ether emulsions as trans-fatty acid-free fat replacers in biscuits: texture and acceptability study. Food Bioprocess Tech 6: 2389-2398, 2013.

[21] Cruz-Romero M, Kelly AL, Kerry JP. Effects of high-pressure and heat treatments on physical and biochemical characteristics of oysters (Crassostrea gigas). Innov Food Sci Emerg 8: 30-38, 2007.

[22] Seczyk L, Swieca M, Dziki D, Anders A, Gawlik-Dziki U. Antioxidant, nutritional and functional characteristics of wheat bread enriched with ground flaxseed hulls. Food Chem 214: 32-38, 2017.

[23] Singleton VL, Rossi JA. Colorimetry of total phenolics with phosphomolybdic-phosphotungstics acid reagents. Am J Enol Vitic 16: 144-158, 1965.

[24] Oyaizu M. Antioxidative activities of browning products of glucosamine fractionated by organic solvent and thin-layer chromatography. Nippon Shokuhin Kogyo Gakkaishi 35: 771-775, 1988.

[25] Lai HY, Lim YY. Antioxidant Properties of Some Malaysian Ferns. Int Proc Chem Biol Environ Eng 20: 8-12, 2011.

[26] Anuradha K, Naidu MM, Manoharb RS, Indiramma AR. Effect of vanilla extract on radical scavenging activity in biscuits. Flavour Fragr J 25: 488-492, 2010.

[27] Mildner-Szkudlarz S, Zawirska-Wojtasiak R, Obuchowski W, Gośliński M. Evaluation of antioxidant activity of green tea extract and its effect on the biscuits lipid fraction oxidative stability. J Food Sci 74: 362-370, 2009.
[28] Sudha ML, Baskaran V, Leelavathi K. Apple pomace as a source of dietary fiber and polyphenols and its effect on the rheological characteristics and cake making. Food Chem 104: 686-692, 2007.

[29] Steel RGD, Torrie JH. Principle and Procedure of Statistics ( $2^{\text {nd }}$ ed). McGraw-Hill, New York, NY, 1980.

[30] Yilmaz F, Dagdemir E. The effects of beeswax coating on quality of Kashar cheese during repening. Int J Food Sci Tech 47: 2582-2589, 2012.

[31] Öğütcü M, Arifoğlu N, Yilmaz E. Storage stability of cod liver oil organogels formed with beeswax and carnauba wax. Int $J$ Food Sci Tech 50: 404-412, 2015.

[32] Calligaris S, Mirolo G, Da Pieve S, Arrighetti G, Nicoli MC. Effect of oil type on formation, structure and thermal properties of $\gamma$-oryzamol and $\beta$-sitosterol-based organogels. Food Biophys 9: 69-75, 2014.

[33] Tomás-Barberán FA, Ferreres F, Tomás-Lorente F. Flavonoids from Apis mellifera beeswax. Zeitschrift für Naturforschung 48: 68-72, 1993.

[34] Bogdanov S. Beeswax: production, properties composition and control. In: Bogdanov, S. editor. Beeswax book. Bee Product Science Publishing, Muehlethurnen, Switzerland, 2009, 1-17.

[35] Grant DL. Beeswax, first draft. WHO food additive series 30. 2005. Available from: http.//www.inchem.org/documents/jecfa/jecmono/v30jell.htm. Accessed 2013 December 12.

[36] Yilmaz F, Ögütcü M, Yuceer YK. Physical properties, volatiles compositions and sensory descriptions of the aromatized hazelnut oil-wax organogels. J Food Sci 80: S2035-2044, 2015. 